Prepared in cooperation with the Federal Emergency Management Agency

\title{
Practical Field Survey Operations for Flood Insurance Rate Maps
}

Open-File Report 2020-1146 



\section{Practical Field Survey Operations for Flood Insurance Rate Maps}

By Nicholas J. Taylor and Caelan E. Simeone

Prepared in cooperation with the Federal Emergency Management Agency

Open-File Report 2020-1146 


\section{U.S. Geological Survey, Reston, Virginia: 2021}

For more information on the USGS - the Federal source for science about the Earth, its natural and living resources, natural hazards, and the environment—visit https://www.usgs.gov or call 1-888-ASK-USGS.

For an overview of USGS information products, including maps, imagery, and publications, visit https://store.usgs.gov/.

Any use of trade, firm, or product names is for descriptive purposes only and does not imply endorsement by the U.S. Government.

Although this information product, for the most part, is in the public domain, it also may contain copyrighted material and images protected by publicity rights. Use of photographs or images may require permission to reproduce copyrighted items or the likeness of a person. Permission must be secured from the copyright owner or person whose likeness is being used. For more information, visit https://usgs.gov/copyright.

Suggested citation:

Taylor, N.J., and Simeone, C.E., 2021, Practical field survey operations for flood insurance rate maps: U.S. Geological Survey Open-File Report 2020-1146, 8 p., https://doi.org/10.3133/ofr20201146.

ISSN 2331-1258 (online) 


\section{Contents}

Abstract

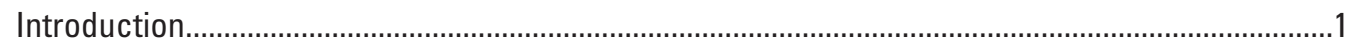

Procedures for Surveying Hydraulic Structures ........................................................................

Hydraulic Structures and Modeled Water Surface Elevations................................................2

Global Navigation Satellite System Specifications and Procedures .........................................2

Reporting Global Navigation Satellite System Error ................................................................

Total Station Specifications and Procedures.........................................................................

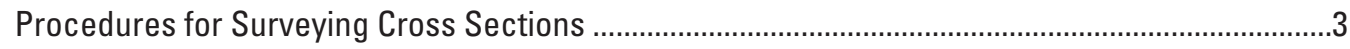

Standards for Lidar Data ........................................................................................................

Global Navigation Satellite System Standards for Cross Sections ............................................

Total Station Standards for Cross Sections...........................................................................

Procedures for Metadata Quality Control ....................................................................................

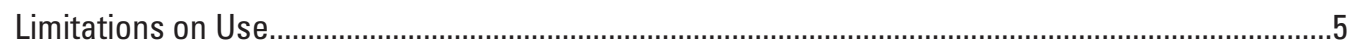

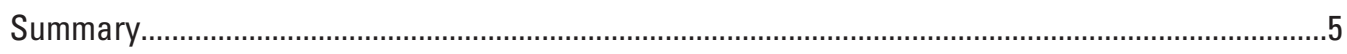

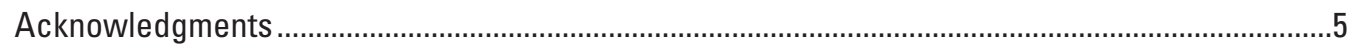

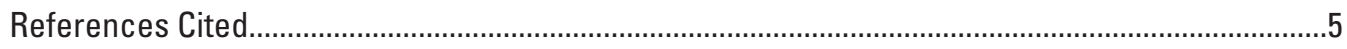

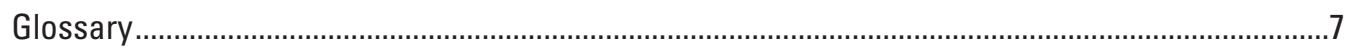

\section{Conversion Factors}

U.S. customary units to International System of Units

\begin{tabular}{|c|c|c|}
\hline Multiply & By & To obtain \\
\hline foot (ft) & 0.3048 & meter (m) \\
\hline mile (mi) & 1.609 & kilometer (km) \\
\hline
\end{tabular}

\section{Datum}

Vertical coordinate information is referenced to the North American Vertical Datum of 1988 (NAVD 88).

Horizontal coordinate information is referenced to the North American Datum of 1983 (NAD 83) within the various State plane coordinate systems.

Elevation, as used in this report, refers to the orthometric height, defined as a distance along a plumb line, from any objective point to the reference height of the vertical datum. 


\section{Abbreviations}

$\begin{array}{ll}\text { FEMA } & \text { Federal Emergency Management Agency } \\ \text { FIRM } & \text { flood insurance rate map } \\ \text { GNSS } & \text { global navigation satellite system } \\ \text { HEC-RAS } & \text { Hydrologic Engineering Center River Analysis System } \\ \text { lidar } & \text { light detection and ranging } \\ \text { OL } & \text { quality level } \\ \text { RTK } & \text { real-time kinematic } \\ \text { RTN } & \text { real-time network } \\ \text { SID } & \text { standard identification } \\ \text { USGS } & \text { U.S. Geological Survey }\end{array}$




\title{
Practical Field Survey Operations for Flood Insurance Rate Maps
}

\author{
By Nicholas J. Taylor and Caelan E. Simeone
}

\begin{abstract}
The U.S. Geological Survey assists the Federal Emergency Management Agency in its mission to identify flood hazards and zones for risk premiums for communities nationwide, by creating flood insurance rate maps through updating hydraulic models that use river geometry data. The data collected consist of elevations of river channels, banks, and structures, such as bridges, dams, and weirs that can affect flow. To account for the model complexity of river structure hydraulics and the fidelity between river channel and structure geometry, two distinct standards for collecting geometry data are presented, both using global navigation satellite system real-time network surveying. This method is adapted from U.S. Geological Survey manuals and is foundational in hydraulic surveying for flood insurance rate maps.
\end{abstract}

\section{Introduction}

The Biggert-Waters Flood Insurance Reform Act of 2012 (Public Law 112-141; 126 Stat. 916) was created to mitigate the risk and effect of flooding on U.S. communities through expanding the Federal Emergency Management Agency (FEMA) National Flood Insurance Program to more accurately incorporate property at risk of flooding (Federal Emergency Management Agency, 2013). Under an interagency reimbursable work agreement, the U.S. Geological Survey (USGS) creates flood insurance rate maps (FIRMs) for FEMA that identify flood hazards and risk premium zones for communities based on updated hydrologic and hydraulic models. The USGS measures the physical dimensions (geometry) of river channels as well as hydraulic and flood-control structures through field surveys; where survey data are not available, the USGS uses light detection and ranging (lidar) data. This report discusses the survey procedures adapted from USGS manuals and optimized for hydraulic models created by the National Flood Insurance Program.

Because FEMA has not published updated survey precision guidelines for river channel and structure data for FIRMs, this report provides a standardized approach to hydraulic surveying by incorporating USGS survey precision standards, as defined by Rydlund and Densmore (2012) and Noll and Rydlund (2020). Floodwater surface elevations and river hydraulics are inferred from surveyed river-geometry data (elevation and horizontal distance along a cross section) and supplementary riverbank and floodplain lidar data using the Hydrologic Engineering Center's River Analysis System (HEC-RAS; U.S. Army Corps of Engineers, 2020).

In a one-dimensional, step-backwater analysis, HECRAS uses an energy loss equation to evaluate water surface elevations along much of a natural river channel, where flow is gradual and linear between observed channel cross sections (U.S. Army Corps of Engineers, 2016). However, for bridge constrictions, dams, and split flows, equations other than the energy loss equation are used to define hydraulic jumps and the intricacies in the geometry of the structures that have a great effect on flow and, ultimately, water surface elevation. To complement the distinct approaches to modeling river hydraulics presented by HEC-RAS, two unique standards for surveying river geometry data are presented: surveying structure geometry and surveying channel geometry.

\section{Procedures for Surveying Hydraulic Structures}

At river structures, rapid contraction and expansion of the river channel and sudden grade breaks can result in substantial water surface elevation changes for a given flow model (Brunner, 2012). To best represent such a structure, HEC-RAS is equipped with multiple routines beyond the standard energy loss equation to model a rapid hydraulic change from permanent river infrastructure (U.S. Army Corps of Engineers, 2016). Because model parameters that define a structure's geometry (for example, low and high chord, abutment, pier, and weir elevations) can be constrained, they are surveyed to the highest precision standard presented in this report. Global navigation satellite system (GNSS) real-time surveying methods described by Rydlund and Densmore (2012, p. 23-27) serve as a guideline for collecting these survey data. 


\section{Hydraulic Structures and Modeled Water Surface Elevations}

Few studies have analyzed model parameter error in estimating the elevation of water surfaces using onedimensional, step-backwater analysis; however, Brunner and Hunt (1995) observed absolute errors between modeled and observed water surface elevations at bridges of 0.24 foot (ft; equivalent to 0.073 meter [m]) in HEC-RAS simulations and $0.33 \mathrm{ft}(0.10 \mathrm{~m})$ in water surface profile computation model (Shearman, 1990) simulations. River hydraulics are largely a product of river geometry. Additionally, at river structures where river hydraulics are often complex, the structure's geometry is often permanent and thus can be surveyed precisely and modeled accurately.

\section{Global Navigation Satellite System Specifications and Procedures}

Rydlund and Densmore (2012) detail the procedures and justifications for obtaining high-precision GNSS data. For surveying FIRMs, the GNSS data are adapted. For surveying structure geometry for hydraulic models, the quality level (QL) II GNSS real-time network (RTN) method was used; this is the highest level of precision the USGS uses for adapting GNSS data to RTNs (Rydlund and Densmore, 2012, table 11). Survey points must pass a variety of metrics to meet QL II standards but importantly must have a vertical precision that is less than $0.16 \mathrm{ft}(0.05 \mathrm{~m})$ for 2 standard deviations $(\sigma)$ of the data (this is the precision solution for the RTN, often expressed as $0.082 \mathrm{ft}(0.025 \mathrm{~m})$ for $1 \sigma$ (Rydlund and Densmore, 2012, table 11). Surveyors use RTNs because it is more efficient than Online Positioning User Service (National Oceanic and Atmospheric Administration, 2020) surveys and provides a greater study area range than single-base realtime kinematic (RTK) surveys. RTNs utilize wireless cellular networks to communicate quality-assurance checks, network modeling, estimation of systematic errors, and calculations of corrected data between networks of fixed receivers and a surveyor's receiver for a given study area (Rydlund and Densmore, 2012, p. 54).

Network coverage can be assessed through the permanent receivers of the respective network, known as continuously operating reference stations. RTNs provide the level of precision needed for the hydraulic models, and although accuracy is difficult to assess with GNSS, additional benchmark checks (defined by the residual from published benchmark elevation and GNSS-derived elevation), produce confidence in the data and quantify error.

Benchmarks are used in developing geoid models to obtain orthometric heights, which are equivalent to elevations for the purposes of this report (Henning, 2014, p. 32-33; Rydlund and Densmore, 2012, p. 3). These benchmarks serve as accurate elevation references for a GNSS survey. Checks of at least two independent benchmarks of National Geodetic Survey first- or second-order vertical standards (Federal Geodetic Control Committee, 1984, table 2.2) should be within the $0.16 \mathrm{ft}$ vertical precision error defined by the RTN solutions. These checks should include at a minimum an initial check before the survey, an additional check on an alternative benchmark, and a final check on the initial benchmark after the survey (more than 3 and less than 24 hours from the initial check). RTK surveys should use benchmarks within a 9-kilometer baseline limit (Rydlund and Densmore, 2012). RTN surveys do not need to adhere to this limit because the baseline is the distance to a virtual base station generated near each observation (Rydlund and Densmore, 2012, fig. 19). At least two benchmarks should be checked regardless of the number of objective points established by the survey. If the observed elevation error on a checked benchmark is greater than $0.16 \mathrm{ft}$, then checks on additional benchmarks are needed; if a consistent error is observed at three or more local benchmarks, then a calibration to benchmarks' elevations, known as a localization, is recommended (Rydlund and Densmore, 2012, p. 46).

\section{Reporting Global Navigation Satellite System Error}

Localizations are rarely necessary because there is often a selection of available benchmarks to obtain an accurate initial check. However, weather or the movement of GNSS satellites can result in a final benchmark check that is greater than the initial check error. If the residual exceeds $0.16 \mathrm{ft}$ for a given benchmark check, then the following steps are taken.

1. All survey objective points measured from the last viable benchmark check are checked with an additional RTN survey and any benchmark (QL II is not necessary for a quick check).

2. Objective points that are reobserved to exceed a $0.16 \mathrm{ft}$ residual from the original elevation are replaced with the new elevation, following QL II procedures (Rydlund and Densmore, 2012, table 11).

This process helps account for blunders in the original survey and unstable benchmarks.

Any error observed should be reviewed first for surveyor blunders before assigning error to a measurement. Blunder check techniques are defined in Rydlund and Densmore (2012, p. 25-26), but two important standards for benchmark blunder checks are that the mean of the two unique observations must be within $0.16 \mathrm{ft}$ of the published elevation and the difference in elevation between observed points cannot be more than $0.1 \mathrm{ft}(0.03 \mathrm{~m})$. Once the desired precision and accuracy is obtained for an objective point, that point can be used as a coordinate reference mark for trigonometric leveling. 


\section{Total Station Specifications and Procedures}

Trigonometric leveling with a total station is used to define the geometry of river structures by referencing two or more RTN points. A total station uses simple geometry to precisely define the coordinates of a new objective point using the known coordinates of a reference mark. The precision of a 5-arc-second total station is plus or minus $0.01 \mathrm{ft}$ $(0.003 \mathrm{~m})$ for sights of $500 \mathrm{ft}$ (152 m; Ghilani and Wolf, 2011, p. 204), which is an order of magnitude more precise than GNSS reference marks. Other sources of error from a total station are from the angle and distance measuring technologies inherent in the instrument. Many modern total stations have autocorrecting technologies to compensate for collimation error, trunnion axis tilt error, sighting error, and atmospheric corrections for electronic distance measurements (Trimble Navigation Ltd., 2015). Sighting in the two faces (direct and reverse instrument orientation) can identify collimation error and trunnion axis tilt error; however, for a properly calibrated instrument, the assumed error inherent with a total station is an order of magnitude less than the error from the GNSSderived reference marks used in this report. Because each type of total station may have different specifications and features, user manuals for individual total stations are used, along with USGS quality control standards and operations of total stations detailed in Noll and Rydlund (2020).

At a minimum, the FIRM surveying standards require maintenance of a calibrated instrument per factory specifications. In addition, the instrument must adapt to the ambient temperature of the surveying site before making corrections (for example, the user manual for the Trimble S7 suggests that the time, in minutes, for the electronic distance measurement to adjust is equal to the temperature, in Celsius, multiplied by 2; [Trimble Navigation Ltd., 2015, p. 69-87]). If using a total station without autocorrecting technologies, sighting for the two faces of the instrument on reference marks for a total station setup, blunder checks (including prism height and offset checks) for objective points, total station setup leveling and stability checks, and atmospheric calibration for electronic distance measurement are required.

A total station is setup over a known point to mitigate the cumulative GNSS measurement error from independent reference marks. This setup involves the following steps:

1. Setup the total station plum over one reference mark, backsight to the second, and foresight to a new reference mark following traverse guidelines in Noll and Rydlund (2020), or foresight to all visible objective points to survey the structure. If a traverse is not necessary to observe all objective points, refer to trigonometric level III specifications under "Sideshot" in table 9 of Noll and Rydlund (2020). To minimize the distance-weighted total station-setup error, the maximum distance between the total station and reference marks ideally should be equivalent to or greater than the maximum distance from the total station to the new objective points.
2. Check the residuals between the observed total station position and the known reference mark. They should not exceed the maximum error in the GNSS reference marks, defined as $2 \sigma$ less than or equal to $0.16 \mathrm{ft}$ or $\sigma$ less than or equal to $0.082 \mathrm{ft}$ for total station elevation.

3. Limit foresight distances to less than $500 \mathrm{ft}$ to minimize atmospheric refraction error (Noll and Rydlund, 2020).

4. If a traverse is needed to establish new reference marks for additional total station setups, follow procedures from Noll and Rydlund (2020) to obtain a trigonometric level II closure errors. If surveying a double-run spur traverse, use the following equation to obtain a trigonometric level II maximum spur-closure error (SCE), in feet (Noll and Rydlund, 2020, table 9):

$$
|S C E| \leq 0.050 \times \sqrt{ } S
$$

where

$S \quad$ is the one-way spur length, in miles.

If surveying a single-run loop traverse, use the following equation to obtain a trigonometric level II maximum loop-closure error (LCE), in feet (Noll and Rydlund, 2020, table 9):

$$
|L C E| \leq 0.050 \times \sqrt{ } L
$$

where

$L \quad$ is the length of the loop, in kilometers.

5. Perform redundant checks on prism and total station heights before and after the survey.

6. Perform a check on an observed reference mark. The maximum elevation difference between redundant check shots should be less than or equal to $0.030 \mathrm{ft}(0.0091 \mathrm{~m}$; Noll and Rydlund, 2020, table 9).

7. Record and report the error from all checks.

\section{Procedures for Surveying Cross Sections}

HEC-RAS hydraulic models use cross sections from surveyed channels to define the natural hydraulic changes along a river. Cross sections are surveyed following FEMA guidance (Federal Emergency Management Agency, 2016, p. 2), with the cross sections spaced so that the geometry and hydraulic roughness of the river between adjacent cross sections varies gradually and variations can be estimated as linear. Although bedforms (ripples and dunes) create visually rough channel geometry, these features are readily altered by flow and do 
not substantially affect a river's hydraulics, and thus are not surveyed. River cross-section data consist of surveyed elevations at channel bottoms and banks as well as supplementary bank and flood plain elevations based on lidar data. FEMA policy includes precision standards for lidar data but not for surveyed elevation data (Federal Emergency Management Agency, 2019b, p. 14-15, SID 40 and 43). Historically, FEMA required lidar data to connect to benchmarks using leveling or GNSS surveying following National Oceanic and Atmospheric Administration (NOAA) guidelines (Zilkoski and others, 1997). Such guidelines were adopted by the USGS in the GNSS surveying manual (Rydlund and Densmore, 2012) along with updated NOAA guidelines (Zilkoski and others, 2008).

\section{Standards for Lidar Data}

FEMA SID 40 (Federal Emergency Management Agency, 2019b) requires that all elevation data meet the USGS National Geospatial Program base lidar specifications (Heidemann, 2018). SID 40 adopts USGS lidar data quality level 2 standards. The updated USGS standards define quality level 2 accuracy at 95th percentile as being less than or equal to $0.643 \mathrm{ft}(0.196 \mathrm{~m})$ for nonvegetated areas and less than or equal to $0.98 \mathrm{ft}(0.30 \mathrm{~m})$ for vegetated areas (Heidemann, 2018, table 4). The latter is a good proxy for the study area because dense vegetation is characteristic of New England riparian areas. To ground-truth these lidar data to GNSS data, elevations should ideally be surveyed at the top or bankfull elevation of river cross sections. Most surveyed data are collected using surveying with a vertical precision equivalent to the lidar data.

\section{Global Navigation Satellite System Standards for Cross Sections}

To obtain the desired survey precision for river cross sections, the GNSS QL IV RTN survey method from Rydlund and Densmore (2012, table 11) was tailored to the purposes of this report. A modified QL IV approach is used rather than a more precise, lower level method because the model's elevation data are ultimately limited by the fidelity of the lidar data (lidar is lower precision than survey GNSS for a point measurement), the collection intervals and duplicate measurements for survey data (required for QLs I through III) are difficult to obtain for a natural channel, and intricate bedform heterogeneities are not incorporated into the hydraulic model. Surveyed elevations thus represent an average channel geometry near cross sections. Considering these factors, the following list of standards and checks were adapted from Rydlund and Densmore (2012, table 11) for quality control of the RTN QL IV data for surveying river cross sections.
- To prevent rod height blunders, the rod height is measured before and after each cross section is surveyed. A fixed-height rod with fixed-height extensions is used for deep water to maintain rod height during wading.

- To prevent GNSS receiver multipathing errors (signal interference from obstructions), satellite masking is increased, and receiver height is adjusted (often increased).

- QL III precision is used for position dilution of precision (error related to the position of satellites) to assure a more stable measurement.

- A collection interval of 1-arc-second is used for five epochs; this was considered to be an ideal collection interval to return a stable root mean square but limit the exposure time of a surveyor to objective hazards when wading a river cross section.

- The root-mean-square error $(2 \sigma)$ of the vertical precision of a GNSS receiver is less than or equal to $0.643 \mathrm{ft}$ (equivalent to the lidar accuracy), although a higher precision of less than or equal to $0.16 \mathrm{ft}$ is often used when RTN solutions are stable.

- To check vertical accuracy of an RTN survey, checks are performed on one published benchmark. This check is performed at the start and end of the RTN survey only, using the same survey collection interval for consistency.

\section{Total Station Standards for Cross Sections}

Riparian vegetation canopy, steep banks, and infrastructure can present obstacles for GNSS surveys along riverbanks. When GNSS methods are not possible, cross sections of the river channel are surveyed using trigonometric leveling with a total station. Channel cross sections are usually surveyed during fall, winter, and early spring months when leaf cover is at a minimum. However, a traverse with a total station from any benchmark or GNSS reference mark can offer an alternative method for surveying cross sections with GNSS obstructions. A loop, spur, or open traverse should follow guidance from Noll and Rydlund (2020). A traverse starts with a station setup over a known reference mark (defined in the "Total Station Specifications and Procedure" section of this report) determined using QL II GNSS standards and at least a QL IV reference mark (Rydlund and Densmore, 2012, table 11) for an azimuth. To finish or "close" any traverse, the first reference mark for a spur or loop traverse must be remeasured from the final station setup to calculate any error (closure error) from the previous setups and measurements. If vertical closure error is greater than trigonometric level III standards (Noll and Rydlund, 2020, table 9), all objective points along the traversed survey path should be resurveyed if the cause of error cannot be determined and corrected. 


\section{Procedures for Metadata Quality Control}

In addition to the procedures detailed in this report, FEMA and the USGS have established specifications for the metadata for a survey (Rydlund and Densmore, 2012; Federal Emergency Management Agency, 2019a; Noll and Rydlund, 2020). Metadata such as position dilution of precision, blunder check results, and number of satellites used should be recorded to constrain survey data to GNSS quality level standards.

Field notes are the primary source for communicating the survey method and associated error for every cross section and structure surveyed. Detailed sketches and site photographs required by the FEMA Data Capture standards (Federal Emergency Management Agency, 2019c) aid in the final construction of structures and channel geometry in HECRAS. Before transcribing data into HEC-RAS, all survey data undergo a two-step review process. After completion of the initial river survey, data are reviewed by a surveyor for projection issues, outlier elevations, missing data, missing metadata, and so on. Excessive errors measured in the field should also be corrected during this initial review. Following the surveyor review, a HEC-RAS modeler reviews survey data for model compatibility.

\section{Limitations on Use}

The survey procedures discussed in this report were adapted from USGS manuals with the purpose of constructing hydraulic models used to produce flood insurance rate maps or similar map products. These products are intended only for the use of the agencies and entities involved in the various cooperative agreements identified in this report.

\section{Summary}

The U.S. Geological Survey (USGS) assists the Federal Emergency Management Agency in its mission to create flood insurance rate maps (FIRMs), which identify flood hazards and zones for risk premiums for communities nationwide. These maps are created by updating hydraulic models using river geometry data. This report documents a standardized approach to surveying river geometry using global navigation satellite system (GNSS) real-time network (RTN) surveying and trigonometric leveling techniques previously established by the USGS. Surveying is divided into two standards based on hydraulic model complexity and changes in water surface elevation. The first approach is used for surveying river structure geometry where rapid hydraulic changes occur where the flow traverses permanent structures. Structure geometry can be surveyed precisely and thus provide an accurate parameter for an otherwise complex model. The second approach is used for surveying river channel geometry, which may have complex bedforms, but often displays more gradual hydraulic and water surface elevation changes.

Techniques for surveying river structures are constrained to GNSS quality level (QL) II reference marks, which can provide accurate elevations to 0.16 foot ( 0.05 meter). Highprecision total stations are then used for detailed geometric surveys by trigonometric leveling at structures. Beyond a structure where a more gradual variation in flow is observed, similar surveying techniques are used to capture channel geometry, but with a lower precision. A GNSS QL IV approach is used rather than a more precise QL II method because elevation data accuracy is limited to the accuracy of the light detection and ranging (lidar) data used in the FIRM, and survey data collection intervals and duplicate measurements (required for QL I through III) are difficult to constrain for a moving channel bed. Thus, channel geometry is represented largely by low-fidelity lidar data, with supplementary elevations from surveyed channels and riverbanks to resolve generalized channel geometry.

\section{Acknowledgments}

The authors thank Salvador Amador, Andrew Massey, Thomas Orcutt, and Terrence Talbot of the U.S. Geological Survey who helped develop and test the surveying procedures detailed in this report.

\section{References Cited}

Brunner, G.W., 2012, Common model stability problems when performing an unsteady flow analysis: Hydrologic Engineering Center presentation, 48 p., assessed February 2, 2021, at https://www.nws.noaa.gov/ ohd $/ \mathrm{hrl} /$ modelcalibration $/ 6 . \% 20 \% 20$ Hydraulic $\% 20$ Model $\% 20$ Calibration/4.1\%20L-11\%20 CommonModelStabilityProblemsInUnsteady $\% 20$ FlowAnalysis.pdf.

Brunner, G.W., and Hunt, J.H., 1995, A comparison of the one-dimensional bridge hydraulic routines from HEC-RAS, HEC-2, and WSPRO: Hydrologic Engineering Center Research Document 41, 80 p., accessed October 3, 2019, at https://apps.dtic.mil/dtic/tr/fulltext/u2/a311030.pdf.

Federal Emergency Management Agency, 2013, Questions about the Biggert-Waters Flood Insurance Reform Act of 2012: Federal Emergency Management Agency, 4 p., assessed February 3, 2021, at https://www.fema.gov/sites/ default/files/2020-07/questions-biggert-waters-floodinsurance-reform-2012.pdf. 
Federal Emergency Management Agency, 2016, HydraulicsOne-dimensional analysis: Federal Emergency Management Agency Guidance Document 80, 16 p., accessed February 3, 2021, at https://www.fema.gov/sites/default/files/2020-02/

Hydraulics_OneDimensionalAnalyses_Nov_2016.pdf.

Federal Emergency Management Agency, 2019a, Data capture technical reference: Federal Emergency Management Agency technical reference, 58 p., assessed October 3, 2019, at https://www.fema.gov/media-library/assets/ documents/34519.

Federal Emergency Management Agency, 2019b, FEMA policy standards for flood risk analysis and mapping (rev. 10, November 2019): Federal Emergency Management Agency Policy FP 204-078-1, 87 p., accessed February, 3, 2021, at https://www.fema.gov/sites/default/files/2020-02/ FEMAPolicyStandardsforFloodRiskAnalysisandMappingNov2019_0.pdf.

Federal Emergency Management Agency, 2019c, Guidance for flood risk analysis and mapping-Data capture-Workflow details: Federal Emergency Management Agency, 58 p., assessed February 3, 2021, at https://www.fema.gov/sites/ default/files/2020-02/Data_Capture_Guidance_Workflow_ Details_Feb_2019.pdf.

Federal Geodetic Control Committee, 1984, Standards and specifications for geodetic control networks: National Oceanic and Atmospheric Administration, 34 p., accessed March 12, 2020, at https://www.ngs.noaa.gov/FGCS/tech_ pub/1984-stds-specs-geodetic-control-networks.pdf.

Ghilani, C.D., and Wolf, P.R., 2011, Elementary surveyingAn introduction to geomatics (13th ed.): Prentice Hall, 984 p.

Heidemann, H.K., 2018, Lidar base specifications (ver. 1.3, February 2018): U.S. Geological Survey Techniques and Methods, book 11, chap. B4, 101 p., accessed July 28, 2020, at https://doi.org/10.3133/tm11B4.

Henning, W.E., 2014, User guidelines for single base real time GNSS positioning (ver. 3.1, April 2014): National Geodetic Survey, 66 p., accessed February 16, 2021, at https://geodesy.noaa.gov/PUBS_LIB/UserGuidelinesForSin gleBaseRealTimeGNSSPositioningv.3.1APR2014-1.pdf.

National Oceanic and Atmospheric Administration, 2020, OPUS - Online positioning user service (ver. 2.6, May 6, 2020): National Oceanic and Atmospheric Administration database, accessed June 18, 2020, at https://www.ngs.noaa.gov/OPUS/.
Noll, M.L., and Rydlund, P.H., Jr., 2020, Procedures and best practices for trigonometric leveling in the U.S. Geological Survey: U.S. Geological Survey Techniques and Methods, book 11, chap. D3, 94 p., accessed January 27, 2021, at https://doi.org/10.3133/tm11D3.

Rydlund, P.H., Jr., and Densmore, B.K., 2012, Methods of practice and guidelines for using survey-grade global navigation satellite systems (GNSS) to establish vertical datum in the United States Geological Survey: U.S. Geological Survey Techniques and Methods, book 11, chap. D1, 120 p., accessed October 1, 2019, at https://doi.org/10.3133/tm11D1.

Shearman, J.O., 1990, WSPRO88 - A computer model for water-surface profile computations: U.S. Geological Survey software, accessed July 22, 2020, at https://water.usgs.gov/ cgi-bin/man_wrdapp?wspro88.

Trimble Navigation Ltd, 2015, User guide Trimble S7 total station: Trimble Navigation Ltd., 121 p., accessed April 1, 2020, at http://www.geoglobex.it/wp-content/uploads/2015/ 07/Trimble-S7-manuale.pdf.

U.S. Army Corps of Engineers, 2016, HEC-RAS—River analysis system: U.S. Army Corps of Engineers user's manual, ver. 5.0, 960 p., accessed July 21, 2020, at https://www.hec.usace.army.mil/software/hec-ras/ documentation/HEC-RAS\%205.0\%20Users $\% 20$ Manual.pdf.

U.S. Army Corps of Engineers, 2020, HEC-RAS: U.S. Army Corps of Engineers Hydrologic Engineering Center website, accessed July 21, 2020, at https://www.hec.usace.army.mil/ software/hec-ras/.

Zilkoski, D.B., Carlson, E.E., and Smith, C.L., 2008, Guidelines for establishing GPS-derived orthometric heights: National Oceanic and Atmospheric Administration Technical Memorandum NOS NGS 59, 19 p., accessed April 1, 2020, at https://www.ngs.noaa.gov/PUBS_LIB/ NGS592008069FINAL2.pdf.

Zilkoski, D.B., D’Onofrio, J.D., and Frakes, S.J., 1997, Guidelines for establishing GPS-derived ellipsoid heightsStandards $-2 \mathrm{~cm}$ and $5 \mathrm{~cm}$ (ver. 4.3, November 1997): National Oceanic and Atmospheric Administration Technical Memorandum NOS NGS-58, accessed April 4, 1, 2020, at https://www.ngs.noaa.gov/PUBS_LIB/ NGS-58.html. 


\section{Glossary}

accuracy How closely global navigation satellite system positioning (or other) measurements represent the "true" elevation. Benchmarks are used to evaluate accuracy during a survey.

backsight $A$ referenced point used during a survey to establish a position.

baseline A computed, three-dimensional vector for a pair of stations for which simultaneous global navigation satellite system data have been collected. Baselines are developed between a single-base real-time kinematic base station and rover, or a real-time network reference station and rover (Rydlund and Densmore, 2012, p. 63).

benchmark A permanent survey mark (monument) designating an exact coordinate at a defined datum. The National Geodetic Survey has specific quality standards that define a benchmark's accuracy and stability. Benchmarks are used in developing geoid models to obtain orthometric heights, known as elevations (Rydlund and Densmore, 2012; Henning, 2014).

blunder A gross error that may cause a measurement uncertainty specification to be exceeded. As opposed to systematic or random errors, blunders are less discrete and are commonly the result of a mistake by the operator during the data collection workflow, such as an incorrect receiver antenna height (Rydlund and Densmore, 2012, p. 63).

datum In geodetic terms, the datum is defined by its reference surface, an origin, an orientation, gravity, and a scale. The North American Datum of 1983 is defined by the Geodetic Reference System of 1980 ellipsoid at an origin near the center of the mass of the Earth with axes oriented through the poles, equator, and at right angles, with a scale unit based on the international meter. The realization of this datum is through a reference, such as benchmark on the ground or global navigation satellite system satellites with the ground control segment (Rydlund and Densmore, 2012, p. 64).

double-run spur traverse A survey in which leveling measurements are made in the forward direction from the origin to the destination and are then retraced along the same leveling route in the backward direction, from the destination to the origin (Noll and Rydlund, 2020).

epoch The time component of the sample frequency for a real-time positioning measurement. Sampling frequency is defined by the number of samples per epoch, and one measurement can contain multiple epochs.

geoid The equipotential surface of the Earth that most closely approximates the global mean sea level. Refined as a hybrid model developed by gravimetric geoids (defined from gravity and terrain data) and separation distances between global navigation satellite system-derived ellipsoid heights and leveled benchmarks. This model is used to convert NAD 83 ellipsoid heights to North American Vertical Datum of 1988 orthometric heights (Rydlund and Densmore, 2012, p. 65).

global navigation satellite system A system of satellites providing autonomous geospatial positioning with global coverage (Rydlund and Densmore, 2012, p. 65).

hydraulic jump A process where abrupt changes in flow velocity cause the water surface of a river to transition from supercritical to subcritical depth. This can occur at river structures, rapid contraction and expansion of the river channels, or sudden grade breaks (U.S. Army Corps of Engineers, 2016).

light detection and ranging (lidar) A method used to measure an object's surface (typically Earth's topography) by emitting pulses of light and measuring the time interval of that light reflecting off a surface and returning to the instrument (Heidemann, 2018, p. 51).

localization Calibration of the global navigation satellite system-derived elevation using a benchmark.

North American Datum of 1983 The official national horizontal datum for the United States depicted as a three-dimensional datum with coordinates of points expressed in latitude, longitude, and ellipsoid height. The origin for the datum is near the center of mass of the 
Earth (Rydlund and Densmore, 2012, p. 66).

\section{North American Vertical Datum of}

1988 Established in 1991 and referenced to the local mean sea level height at Rimouski, Quebec, Canada, in the International Great Lakes Datum of 1985 (Rydlund and Densmore, 2012, p. 66).

objective point An established point from a survey, known as a foresight (Rydlund and Densmore, 2012, p. 67).

Online Position User Service A software service by the National Geodetic Survey to provide access to a network of continuously operating reference stations' coordinates; Online Position User Service uses software to compute coordinates using the National 0 ceanic and Atmospheric Administration Continuously Operating Reference Station Network (Rydlund and Densmore, 2012, p. 66).

open traverse $A$ trigonometric-leveling survey used to establish vertical control that originates at a point of known location and terminates at a point of unknown location (Noll and Rydlund, 2020).

precision The consistency from measurements of the same thing. Often quantified using standard deviation.

real-time kinematic, single-base A traditional relative positioning procedure whereby observables and corrections for each antenna signal to each common satellite are transmitting in real time from a base station to the user's rover receiver. The rover receiver processes the data in real time. Centimeter-level accuracy is achieved without any postprocessing (Rydlund and Densmore, 2012, p. 67).

real-time network A statewide network of continuously operating reference stations that are municipally, State, or privately owned. A centralized server is used to facilitate quality assurance checks, network modeling, estimation of systematic errors, and calculation of corrected data that is submitted back to the end user at the rover position. The network operates by use of cellular communication, which eliminates the requirement for a traditional base station to be used in the field (Rydlund and Densmore, 2012, p. 68). reference station (base station) An autonomous station that relays differentially corrected position data from satellites to a rover.

root mean square Mathematically, the square root of the average of the sum of the squared residuals from the computed value; statistically, a measure of predictive power depicted as a spread of the results. For real-time positioning, root mean square error is usually expressed as $x, y$, and $z$ at the 68 percent (or 1 standard deviation [ $\sigma]$ ) level of confidence. These values should be doubled to express at the 95-percent (or $2 \sigma$ ) confidence level (Rydlund and Densmore, 2012, p. 68).

rover A global navigation satellite system receiver that receives differential corrections from a reference station to accurately measure the position of an objective point (Rydlund and Densmore, 2012, p. 68).

single-run loop traverse Leveling measurements for a single-run loop traverse are made in the forward direction from the origin point to the destination, and then from the destination to the origin point, along a different leveling route. The only point that is redundantly occupied for the single-run loop traverse is the origin (Noll and Rydlund, 2020).

total station A surveying instrument equipped with both a zenith angle measuring device (theodolite) and a slope distance measuring (electronic distance measuring) device to determine the horizontal and vertical position of an unknown point (objective point) in reference to a known point (reference mark) through trigonometric leveling (Noll and Rydlund, 2020).

traverse A surveying technique where objective points are set and then used as reference marks in order to move the total station along a path. Traverses can be either open or closed. A closed traverse terminates on a known point and results in higher precision data than an open traverse (Noll and Rydlund, 2020).

virtual base station An artificially generated base station that is generated near the rover locations based on an interpolation of surrounding reference stations. 
Director, New England Water Science Center

U.S. Geological Survey

10 Bearfoot Road

Northborough, MA 01532

dc_nweng@usgs.gov

or visit our website at

https://www.usgs.gov/centers/new-england-water

Publishing support provided by the

Pembroke Publishing Service Center 


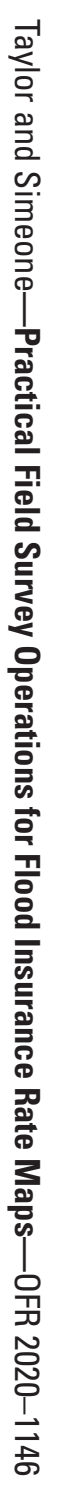

